\title{
Is the quality of primary healthcare services influenced by the healthcare centre's type of ownership?-An observational study of patient perceived quality, prescription rates and follow-up routines in privately and publicly owned primary
} care centres

Andy Maun ${ }^{1,2,3^{*}}$, Catrin Wessman ${ }^{3,4}$, Pär-Daniel Sundvall ${ }^{3,5}$, Jörgen Thorn ${ }^{3}$ and Cecilia Björkelund ${ }^{3}$

\begin{abstract}
Background: Primary healthcare in Sweden has undergone comprehensive reforms, including freedom of choice regarding provider, freedom of establishment and increased privatisation aiming to meet demands for quality and availability. In this system privately and publicly owned primary care centres with different business models (for-profit vs non-profit) coexist and compete for patients, which makes it important to study whether or not the type of ownership influences the quality of the primary healthcare services.

Methods: In this retrospective observational study (April 2011 to January 2014) the patient perceived quality, the use of antibiotics and benzodiazepine derivatives, and the follow-up routines of certain chronic diseases were analysed for all primary care centres in Region Västra Götaland. The outcome measures were compared on a group level between privately owned $(n=86)$ and publicly owned $(n=114)$ primary care centres (PCC).

Results: In comparison with the group of publicly owned PCCs, the group of privately owned PCCs were characterized by: a smaller, but continuously growing share of the population served (from 32 to $36 \%$ ); smaller PCC population sizes (avg. 5932 vs. 9432 individuals); a higher fraction of PCCs located in urban areas (57\% vs 35 \%); a higher fraction of listed citizens in working age (62\% vs. $56 \%$ ) and belonging to the second most affluent socioeconomic quintile ( $26 \%$ vs. $14 \%$ ); higher perceived patient quality (82.4 vs. 79.6 points); higher use of antibiotics (6.0 vs. 5.1 prescriptions per 100 individuals in a quarter); lower use of benzodiazepines (DDD per 100 patients/month) for 20-74 year olds (278 vs. 306) and >74 year olds (1744 vs.1791); lower rates for follow-ups of chronic diseases (71.2 \% vs $74.6 \%$ ). While antibiotic use decreased, the use of benzodiazepines increased for both groups over time.

(Continued on next page)
\end{abstract}

\footnotetext{
* Correspondence: andy.maun@gu.se

'Department of Medicine, Division of General Practice, University Medical Centre Freiburg, Elsässerstr. 2 m, D-79110 Freiburg, Germany

${ }^{2}$ Institute for Quality Management and Social Medicine, University Medical

Centre Freiburg, Engelbergerstr. 21, D-79106 Freiburg, Germany

Full list of author information is available at the end of the article
} 
(Continued from previous page)

Conclusions: The findings of this study cannot unambiguously answer the question of whether or not the quality is influenced by the healthcare centre's type of ownership. It can be questioned whether the reform created conditions that encouraged quality improvements. Tendencies of an (unintended) unequal distribution of the population between the two groups with disparities in age, socio-economy and geography might lead to unpredictable effects. Further studies are necessary for evidence-informed policy-making.

Keywords: Health services research, Primary healthcare, Privatisation, Public sector, Private sector, Government policy, Reform, Quality improvement, Economic competition, Scandinavia

\section{Background}

From the perspective of citizens and patients, it is most important that healthcare reforms lead to an efficient use of resources with access to healthcare that is knowledgebased, efficient, safe, patient-focused, equitable and timely [1]. In order to meet demands for quality and availability in primary healthcare, Sweden has carried out comprehensive reforms in recent years, including freedom of choice regarding provider, freedom of establishment and increased privatisation [2].

The Swedish health care system is a socially responsible system with an explicit public commitment to ensure the health of all citizens and follows the principles of human dignity, need and solidarity, and costeffectiveness [3]. Health care expenditure in Sweden is mainly tax funded ( $80 \%)$, user charges for visits to professionals, hospitalization and medicines fund about $17 \%$ and primary care constitutes for around $20 \%$ of the total healthcare budget [3]. Primary care in Sweden is delivered by more than 1100 publicly and privately owned primary care centres (PCC) throughout the country.

The recent reform means that the County Councils only define the assignment and reimbursement schemes and may not decide who is to provide care or where it will be carried out. It also means that providers that fulfil general quality requirements have the freedom of establishment (without any geographical restrictions or limitations in numbers) and that the providers are competing for patients. The aim of these reforms were, according to the government, to focus on the individual and to shift power away from politicians and officials to citizens, thus increasing citizens' choice and influence as well as increasing the number of providers and their diversity. The government argued that the reforms would create conditions that encourage care providers to improve the quality and efficiency of care, as the compensation comes with the patients who will seek the best provider according to their preferences. All PCCs have to ensure equal access to their listed citizens according to their medical conditions and cannot refuse citizens to register. Individuals seeking care should be able to get in touch with the PCC the same day (availability guarantee) and should be given an appointment with a doctor within 7 days from the time of initial contact, provided that the caregiver has determined that the person needs to visit a doctor (visiting warranty). Citizens can at any time without any restrictions choose to leave a PCC and register at another PCC of their choice and may not be rejected [4]. In the majority PCCs are either publicly owned by the primary care organisations of the county councils or privately owned by healthcare corporations, only a minority of PCCs are privately owned by their operators. The absolute majority of the numerous recently established PCCs are privately owned [4]. Each provider organization decides independently the rate of the salary and working conditions such as the number of patients or patient visits per General Practitioner (GP). Due to a lack of GPs in Sweden there is also a recruitment competition between primary care centres. Regardless of their ownership type all PCCs in a county are compensated using the same model. Each of the provider organisations or corporations has solely financial responsibility for their PCCs. Providers may support units that go in debt within their organsation or, if accessible, through external financial support e.g. investments of their shareholders. In the studied Region Västra Götaland the compensation for PCCs is mainly based on capitation (90\%), with adjustments for age, gender and the morbidity burden of their patient population as determined by the John Hopkins Adjusted Clinical Groups System based on the registered diagnoses for the individual patient [5]. The remaining $10 \%$ of the compensation is based on geographical and socioeconomical factors, structural goals, patient-satisfaction and pay-for-performance schemes (3\%). The compensation has to cover operating costs of the PCC including the salaries, the budget for prescribed medications and diagnostic tests such as laboratory and radiologic examinations. If profits are generated after deduction of costs, publicly owned provider organisations have to reinvest them in their organisation, while privately owned provider organisations can pay out a divident to their shareholders.

As the aims of these reforms have been to strengthen the role of the patient and to improve accessibility and quality, the Swedish Association of Local Authorities and Regions (SALAR) annually conducts a national patient survey and publishes the results for each PCC in the 
country. Moreover a number of studies have been carried out to monitor the ambiguous effects of the reforms. About $60 \%$ of the population in three larger Swedish counties perceived that they had made a choice of provider after the introduction of the reforms [6]. There were no clear signs of absolute displacement effects, i.e. that certain patient groups increased their utilisation of health services while others reduced it, but the population as a whole had increased its utilisation to a greater extent than people with major care needs [7]. Primary care managers of publicly owned centres found it more difficult to prioritise correctly between patient groups with different needs, demands and levels of empowerment and were concerned about potentially negative effects on less empowered persons [8]. While the general public and the patients attending primary care scored higher satisfaction rates after the reforms-people with higher incomes in particular showed higher satisfaction rates with the development of accessibility-staff experienced a certain degree of deterioration $[7,9]$.

In this environment with strong economic incentives and an intense competition among PCCs for listed patients and in the recruitment of GPs, medical decisions might be compromised for economic reasons. Additionally the structural difference between coexisting non-profit and for-profit organisations has to be considered, which has been object of earlier controversies criticizing higher costs and lower quality of for-profit organisations [10-12]. As earlier studies showed effects of financial incentives on medical practice and suggest to rigorously evaluate the impact of changes in the payment system, these conditions make it important to study whether or not the quality of the primary healthcare services available is influenced by the PCCs' type of ownership $[13,14]$.

This study focuses on outcomes that possibly can be influenced by the given incentives. The assumption is that PCCs are likely to strive after high patient satisfaction to maintain or increase the numbers of patients listed. However, research has shown that higher patient satisfaction can be associated with higher overall health care and prescription drug expenditures and paradoxically can even be associated with increased mortality [15].

Despite the fact that an increased use of antibiotics heightens the probability of antibiotic resistance in the population, a prior study showed that patients' expectations had a significant influence on the prescription of antibiotics. Patients who were not prescribed an antibiotic that they wanted were more likely to be dissatisfied and to re-consult twice $[16,17]$. One concern is that physicians might be influenced in their medical decisions in order to avoid either more frequent re-consultation by dissatisfied patients (without being reimbursed for that effort) or that physicians fear that patients may choose to register themselves at another primary healthcare centre. Similar effects could be apprehended for the prescription rates of benzodiazepine derivatives: despite the fact that these are only recommended for short periods of treatment and regular use is associated with negative health effects such as addiction [18], prescription rates in the county studied have been the highest in the country for decades and have exceeded US levels threefold [19]. The assumption is physicians might be influenced in their medical decisions when conflicts of interest between the physician and the patient arise that can be time-consuming or have an impact on the patient's satisfaction and choice of the primary care provider. As the compensation is partly based on the morbidity burden documented by the registered diagnoses for the individual patient, it is also of interest to study and compare the rates of follow-ups actually carried out for chronic conditions where reliable information is available.

The aim of this study is to compare privately and publicly owned PCCs in Region Västra Götaland in Sweden on a group level concerning the quality of care provided. The study focuses on patient perceived quality, rates of purchased prescriptions of antibiotics and benzodiazepine derivatives as well as the percentage of follow-up routines carried out for patients with the chronic diseases diabetes mellitus, chronic ischemic heart disease and hypertension.

\section{Methods}

\section{Study design}

This study is a descriptive analysis of all accessible PCCs in Region Västra Götaland. Hence it is a retrospective observational cohort study at the level of PCC. Quality standards for observational studies were assured through the application of the STROBE 22-item checklist (items addressed below) [20].

\section{Eligibility criteria}

All contracted PCCs located in Region Västra Götaland during the period between April 2011 and January 2014 were included. In January 2014 there were 201 PCCs (approved by the regional healthcare authorities) that served $99.9 \%$ of the population of 1.6 million citizens. The small number of single-handed practices serving a very small proportion of the population on a regular basis $(<1 \%)$ and Out-of-hours services organised in clusters of PCCs were excluded from the analysis because they had particular assignments and very little data for these activities was available.

\section{Data sources and data collection}

All datasets were publicly available from the regional healthcare authorities [21] and were already aggregated on PCC level and thus do not contain data on the level of the individual citizen. The datasets included information on productivity and a number of quality outcome 
measurements which the authority collected from the PCCs' electronic administrative systems, the administrative agency Statistics Sweden [22], the national patient survey [23], the National Prescribed Drug Register [24], the Swedish eHealth Agency [25], the National Diabetes Register (NDR) [26] and the regional Quality Registry for chronic diseases (QregPV) [27]. As all PCCs have only been obliged to approve data collection by the regional healthcare authorities since April 2011, no data prior to that was available. All datasets were either on a monthly or annual basis.

\section{Variables}

The following datasets of independent variables of the PCCs were included in the study:

1. The ownership type of the PCC: either privately or publicly owned (completeness rate $100 \%$ ).

2. The geographical location of the PCC: as earlier research indicated structural differences in primary care in terms of density and new establishment rates of PCC and patient perceived quality $[4,28]$ between densely and more sparsely populated areas the research team divided all PCCs into two groups; either belonging to the metropolitan area of Gothenburg (within $20 \mathrm{~km}$ range) or not (completeness rate $100 \%$ ).

3. The number of citizens listed at the PCC on an average yearly basis (completeness rate $100 \%$ ).

4. The proportion of female and male citizens listed at the PCC on a yearly basis (completeness rate $100 \%$ ).

5. The proportional size of the three different age groups (aged below 20, aged 20-64 and aged 65 and above) of citizens listed at the PCC on a yearly basis. As data was only available in age groups at 5-year intervals the research team chose to combine the data into three groups that have qualitatively different primary care needs (completeness rate $96.6 \%$ ).

6. The socioeconomic index of the listed population on an average yearly basis: as prior research has shown that PCC populations differ greatly in socioeconomic status, which has an impact on the prevalence of multi-morbidity on a group level, the Care Need Index (CNI) for each PCC was included $[29,30]$. The administrative agency Statistics Sweden regularly calculates the $\mathrm{CNI}$ for each $\mathrm{PCC}$ by the regionally-adjusted factors age, family status, educational status, employment status and migration status (completeness rate $100 \%$ ).

The following datasets of dependent variables of the PCCs were included in the study:

1. Patient Perceived Quality: The annual results of the national patient survey (NPS) 2011-2013 expressed by the weighted Patient Perceived Quality (PPQ) values between 0 (minimum) and 100 (maximum) [23]. SALAR randomly selected annually 39,000 patients in the Västra Götaland Region who visited a PCC in September and sent them a letter with questions concerning perceived service, participation, information, accessibility, confidence, usefulness, recommendation, and overall impression. The research team selected the four variables from the NPS considered most relevant for this study: the mean PPQ value; the value that measures to what extent the patient would recommend the PCC to other patients; the value that measures the perceived accessibility to the PCC; and the value that measures the perceived interpersonal continuity. However, even if the completeness rate of datasets for all PCCs was high $(97.4 \%)$ it has to be considered that the response rates of the annual NPS were between 51.3 and $53.4 \%$ and that results are negatively confounded in socio-economic disadvantaged and urban districts. Therefore the results of the NPS have to be interpreted with caution.

2. Rate of purchased antibiotics prescribed at a PCC: The Public Health Agency of Sweden and the Swedish Strategic Programme Against Antibiotic Resistance (Strama) continuously follow up the total antibiotic use in the population on a monthly, quarterly, and yearly basis [31]. This study does not count the actual number of prescriptions made at a PCC but uses a proxy measure to describe the antibiotic use at a PCC: through data from the Swedish eHealth Agency the number of purchased antibiotics per 100 individuals listed at a PCC is calculated for each quarter of a year. Due to permanent changes in the number of listed individuals this quote is calculated for each month of a quarter. Drugs with the Anatomical Therapeutic Chemical classification (ATC) code J01 are included in this follow-up, except for the antiseptic substance methenamine hippurate J01XX05 which is not an antibiotic and has no influence on antibiotic resistance. Throughout this paper, methenamine hippurate is consequently excluded whenever antibiotics are referred to. This proxy measure for antibiotic use is neither adjusted for age nor gender, nor is it necessarily connected to the patients listed at the PCC. (Completeness rate $95.6 \%$ ).

3. Rate of purchased benzodiazepine derivatives prescribed at a PCC: the rate for the monthly use of benzodiazepine derivatives is expressed by the quotient of defined daily doses (DDD) [32] per 100 listed individuals visiting the $\mathrm{PCC}$ in the same month. The DDD is based on the assumed average dose per day for the drug given to adults for its 
main indication. The calculation included the DDD of prescribed benzodiazepine derivatives with the ATC codes N05BA, N05CD, N05CF that were purchased at pharmacies. As the rates were already divided into subgroups for younger (20-74 years old) and older ( $>74$ years old) patients by the regional healthcare authority (because rates differ considerably for these two age groups) these age strata differ from the rest of the analysis (completeness rate 95.4\%) [18].

As only reliable data was available for patients with diabetes mellitus (DM), ischemic heart disease (IHD) and hypertension (HPT) concerning follow-up routines that had been carried out, only these chronic conditions were included in the study.

4. Annual rate of follow-up routines that were carried out for patients of all age groups with DM: the rate was calculated through the quotients of measurements documented at least once annually for glycated haemoglobin (HbA1c), blood pressure, body mass index (BMI), smoking habits, urine micro-albumin and low-density lipoprotein (LDL) and the number of patients with the diagnosis DM (completeness rate $99.6 \%$ ).

5. Annual rate of follow-up routines that were carried out for patients of all age groups with IHD: the rate was calculated through the quotients of smoking habits and measurements of blood pressure and LDL documented at least once annually and the number of patients with the diagnosis IHD. Data was only available for 2012 (completeness rate $89.5 \%$ ).

6. Annual rate of follow-up routines that were carried out for diagnosed HPT for all patients aged 18-79 with solely HPT (absence of DM or IHD): the rate was calculated through the quotients of measurements documented at least once annually for blood pressure and smoking habits and the number of patients with the diagnosis HPT. Data was only available for 2012 (completeness rate $97.1 \%$ ).

Due to technical or other reasons unknown to the research group at the regional healthcare authorities during the collection of data from the above-mentioned sources, minor percentages of datasets were missing. For integrity reasons the NPS did not publish data for PPQ when the total number of individuals in a dataset was very low $(n<30)$. The research group did not actively exclude any of the data received.

As all data reflects only calculated measures of the actual month or year for each PCC, data from PCCs that closed down or were newly-opened was included during the time of their existence.
All PCCs were divided into the two groups of privately and publicly owned PCCs. In some contexts further subgrouping into socioeconomic quintiles or geographical location was applied.

\section{Data analysis of the total population}

Descriptive statistic calculations of the independent variables (sample sizes and demographic characteristics expressed through mean values and standard deviations (SD)) were conducted for the groups of privately and publicly owned PCCs respectively including the changes over time. All data analysed was already aggregated at the PCC level-where the new economic incentives applied to all units in exactly the same way-using the same methods and time intervals for data collection with very low fractions of missing data. As the analysis carried out was a study of a total population with very high rates of data completeness, no power calculation and/or tests for statistical significance were performed. Instead the mean values and standard deviations of the dependent variables were calculated. In the case of antibiotic use the $10^{\text {th }}, 50^{\text {th }}$ and $90^{\text {th }}$ percentiles were used to statistically describe the different subgroups' results (high prescribing and low prescribing PCCs respectively). As these statistical descriptions do not include the adjustments for explanatory factors the analysis was supplemented with the results of a linear mixed model including confidence intervals for repeated yearly observations in order to investigate for possible confounders. This mixed model can be split into two components: a "random" effect and a "fixed" effect. The random effect is that that PCCs have a random intercept (starting point) in their variables. In this way individual variation between the centres was considered. The fixed effect is manifested in all other parameters: type of ownership, geographical location, year etc. The residuals of this model based on annual data showed a homogeneity of variances and only little tendencies to skewness why the research group assessed that this model was viable in this study and refrained from using a multilevel model as all data was analysed at the level of the PCCs not aiming to attain any conclusions at the level of the individual citizen. The estimates, standard deviations and $95 \%$ confidence intervals in this used model reveal the influence of the confounding factors, their variance and in which way results for the two groups change when adjusted for the confounding factors.

The mean patient perceived quality value was adjusted for CNI, number of listed citizens and location of each PCC as these factors showed influence in an earlier study [28]. The prescription rates of antibiotics and benzodiazepine derivatives were adjusted for CNI, proportion of gender groups and location of each PCC as these factors have shown influence earlier $[18,33,34]$. In the case of the antibiotic use the rate was also adjusted according to the 
proportion of age groups (0-19 years, 20-64 years and $65+)$ listed at PCC. For the outcome measures of the chronic diseases no adjustments were conducted as all PCCs were expected, according to regional guidelines, to carry out basic follow-up measurements as such as documentation of blood pressure and smoking habits regardless age, socioeconomic status, location or size of the PCC. In the few cases of missing data, PCCs were excluded from the calculations. All data was analysed using SPSS v22 and SAS v9.3.

\section{Ethical considerations}

No data on individual patients was handled. According to Swedish law this aggregated data on the level of the PCC is public and not liable to any confidentiality which is why no ethical approval was necessary for this study.

\section{Results}

Descriptive data on the characteristics of the participating primary care centres

The characteristics of the PCCs studied are presented in Table 1: the 200 PCCs provided primary care services for 1.6 million citizens (99.7\% of the total population). $57 \%(114 / 200)$ were publicly owned and $43 \%(86 / 200)$ were privately owned. There were minor fluctuations with a small number of PCCs $(n=6)$ that closed down and or had just opened during the period studied but the total number of PCCs in the two compared groups remained stable with in sum only one additional privately owned PCC. From a geographical perspective $44 \%$ of all PCCs were located within a $20 \mathrm{~km}$ range of the regional metropolis, an area where privately owned PCCs were overrepresented accounting for $54 \%$ of all PCCs in that area. The population within this metropolitan area was younger compared with the population outside this area.

The PCCs in the two groups differed considerably in the number of listed patients with a mean of approximately 5900 listed citizens at privately owned PCCs and 9400 listed citizens at publicly owned PCCs. During the period studied the mean size of the privately owned PCCs grew to 6700 listed citizens, while the mean size of the publicly owned PCCs shrank to 9100 listed citizens, reflecting the fact that the listed population at privately owned centres grew by 70,181 citizens, while the listed population at publicly owned centres decreased by 42,866 citizens (including a population growth in the county of 24,480 citizens).

There were only minimal differences between the two groups in the size of the gender groups of the listed citizens (difference $0.45 \%$ ). While the group of citizens of working age (aged 20-64) was steadily overrepresented at privately owned PCCs $(62.4 \%$ compared to $56.0 \%)$, the groups of citizens aged 0-19 and over 64 showed a small but steady overrepresentation at publicly owned
PCCs $(23.4 \%$ compared to $20 \%$ for the younger group and $20.6 \%$ compared to $17.6 \%$ for the older group).

The socioeconomic indices of all PCCs varied mainly between CNI 1.03 (most affluent) and CNI 8.06 (least affluent) with a mean CNI of 2.33 in January 2014. The mean CNIs of the two groups of PCCs showed only small differences, but the group of privately owned PCCs had a higher variance in CNI (privately owned PCCs mean CNI 2.36, SD 0.912 vs. publicly owned PCCs mean CNI 2.32, SD 0.632) which indicates that their listed populations had a higher degree of segregation. As shown in Table 1 a comparison that also considered the different sizes of the PCC revealed for the group of privately owned PCCs that the fraction of citizens representing the second most affluent quintile was overrepresented at the cost of an underrepresentation of the fraction representing the second least affluent quintile $\left(2^{\text {nd }}\right.$ quintile $26 \%, 4^{\text {th }}$ quintile $12 \%$ ). The reverse findings applied for the group of publicly owned PCCs ( $2^{\text {nd }}$ quintile $14 \%, 4^{\text {th }}$ quintile $25 \%$ ).

The observation of changes in the characteristics of the two groups during the period studied showed that the population growth in the county (27.315 citizens) and the transfer of citizens from publicly owned to privately owned PCCs (42.866 citizens) were continuous (Fig. 1). The majority of recently listed citizens at privately owned PCCs belonged to both the socioeconomically least affluent and most affluent populations, while the citizens who signed off from publicly owned centres mainly belonged to populations with average to low socioeconomic status (Fig. 2).

\section{Main results}

\section{Patient perceived quality}

The unadjusted results of the national survey of patient perceived quality (Table 1) showed that the group of privately owned PCCs in 2011 received higher levels of satisfaction ratings than the group of publicly owned PCCs (mean value 82.4 compared to 79.6), especially in the item perceived continuity (70.4 compared to 58.2) and the item reflecting whether the patient would recommend the centre to others (86.3 compared to 81.7). Until 2013 the values decreased on average $1.2 \%$ in both groups maintaining the order between the two groups. As confounding factors in the national survey of patient perceived quality are known through previous research, the results were adjusted for mean CNI, geographic location and size of the PCC. After adjustment, privately owned PCCs showed still higher values of mean patient perceived quality (Table 2). Populations that were less affluent and populations outside the regional metropolis tended towards a lower rating of patient perceived quality. The number of listed citizens of the PCC had also a small negative effect. However these results have to be interpreted with caution considering 
Table 1 Demographic characteristics of privately and publicly owned primary care centres (PCC)

\begin{tabular}{|c|c|c|c|c|c|c|c|c|c|c|c|c|c|c|c|}
\hline & \multicolumn{5}{|c|}{ Privately owned PCC } & \multicolumn{5}{|c|}{ Publicly owned PCC } & \multicolumn{5}{|l|}{ all PCC } \\
\hline & no. of PHCC & \multicolumn{2}{|c|}{$\begin{array}{l}\text { no. of listed citizens, } \\
\text { (\% of the pop.) }\end{array}$} & \multicolumn{2}{|c|}{$\begin{array}{l}\text { mean listed } \\
\text { citizens/PHCC } \\
\text { (SD) }\end{array}$} & $\begin{array}{l}\text { no. of } \\
\text { PHCC }\end{array}$ & \multicolumn{2}{|c|}{$\begin{array}{l}\text { no. of listed citizens, } \\
\text { (\% of the pop.) }\end{array}$} & \multicolumn{2}{|c|}{$\begin{array}{l}\text { mean listed } \\
\text { citizens/PHCC } \\
\text { (SD) }\end{array}$} & $\begin{array}{l}\text { no. of } \\
\text { PHCC }\end{array}$ & \multicolumn{2}{|c|}{$\begin{array}{l}\text { no. of listed citizens, } \\
\text { (\% of the pop.) }\end{array}$} & \multicolumn{2}{|c|}{$\begin{array}{l}\text { mean listed } \\
\text { citizens/PHCC } \\
\text { (SD) }\end{array}$} \\
\hline April 2011 & 86 & \multicolumn{2}{|c|}{$510,123(32.1 \%)$} & \multicolumn{2}{|c|}{5931.7 (3426.29) } & 114 & \multicolumn{2}{|c|}{ 1,075,225 (67.6\%) } & \multicolumn{2}{|c|}{$9431.8(3931.52)$} & 200 & \multicolumn{2}{|c|}{ 1,585,348 (99.7\%) } & \multicolumn{2}{|c|}{$7926.7(4099.90)$} \\
\hline January 2014 & 87 & \multicolumn{2}{|c|}{580,304 (35.9 \%) } & \multicolumn{2}{|c|}{$6670.2(3495.72)$} & 114 & \multicolumn{2}{|c|}{ 1,032,359 (63.9\%) } & \multicolumn{2}{|c|}{$9055.8(3768,60)$} & 201 & \multicolumn{2}{|c|}{ 1,612,663 (99.9\%) } & \multicolumn{2}{|c|}{$8023.2(3830.67)$} \\
\hline \multirow[t]{6}{*}{ Change, (RG) } & +1 (+1.1\%) & \multicolumn{2}{|c|}{$+70,181(+12.1 \%)$} & \multicolumn{2}{|c|}{ +738.5 (+11,1\%) } & $0(0)$ & \multicolumn{2}{|c|}{$-42,866(-4.2 \%)$} & \multicolumn{2}{|c|}{$-375(-4.2 \%)$} & +1 (+0.5\%) & \multicolumn{2}{|c|}{$+27,315$ (+1.7\%) } & \multicolumn{2}{|c|}{$96.5(+1.2 \%)$} \\
\hline & geographic lo & ocation: w & ithin or outs & side the res & ional metropoli & is, percenta & e of PCCs & within their & group & & & & & & \\
\hline & & within & & outside & & & within & & outside & & & within & & outside & \\
\hline & & $56.9 \%$ & & $43.1 \%$ & & & $34.5 \%$ & & $65.5 \%$ & & & $44.0 \%$ & & $56.0 \%$ & \\
\hline & gender in per & rcentage & of listed citiz & & & & & & & & & & & & \\
\hline & & female & & male & & & female & & male & & & female & & male & \\
\hline April 2011 & & $49.61 \%$ & (0.035) & $50.39 \%$ & .035) & & $49.83 \%$ & $0.018)$ & $50.17 \%$ & .018) & & $49.72 \%$ & $0.027)$ & $50.28 \%$ & $027)$ \\
\hline January 2014 & & $49.55 \%$ & $(0.036)$ & $50.45 \%$ & .036) & & $49.78 \%$ & $0.018)$ & $50.22 \%$ & .018) & & $49.68 \%$ & $0.027)$ & $50.32 \%$ & $.027)$ \\
\hline & fraction of citi & tizens with & in each grou & up belong & hg to age group & ps (aged 0 & $19,20-64$, & $>64)$ & & & & & & & \\
\hline & $0-19$ & & $20-64$ & & $>64$ & $0-19$ & & $20-64$ & & $>64$ & 0-19 & & $20-64$ & & $>64$ \\
\hline April 2011 & $20.1 \%(0.06)$ & & $62.4 \%(0.0$ & & $17.5 \%(0.06)$ & $23.4 \%$ & & $56.2 \%(0$. & & $20.4 \%(0.05)$ & $21.9 \%(0.06$ & & $58.9 \%(0.0$ & & $19.2 \%(0.06)$ \\
\hline January 2014 & $20.0 \%(0.06)$ & & $62.4 \%(0.0$ & & $17.6 \%(0.06)$ & $23.4 \%$ & & $56.0 \%(0$. & & $20.6 \%(0.05)$ & $21.9 \%(0.06$ & & $58.8 \%(0.0$ & & $19.3 \%(0.06)$ \\
\hline & mean of Care & e Need Inc & & & & & & & & & & & & & \\
\hline April 2011 & $2.36(0.912)$ & & & & & 2.32 & & & & & $2.34(0.762)$ & & & & \\
\hline January 2014 & $2.36(1.034)$ & & & & & 2.30 & & & & & $2.33(0.844)$ & & & & \\
\hline & fraction of citi & tizens with & in each grou & up listed a & PCC belonging & to quintile & $1-5$ of $\mathrm{Ca}$ & e Need Inde & $\mathrm{ex}(1=\mathrm{mo}$ & affluent, $5=$ le & ast affluent) & & & & \\
\hline & CNI Q1 & CNI Q2 & CNI Q3 & CNI Q4 & CNI Q5 & CNI Q1 & CNI Q2 & CNI Q3 & $\mathrm{CNI}$ Q4 & CNI Q5 & CNI Q1 & CNI Q2 & CNI Q3 & CNI Q4 & CNI Q5 \\
\hline & $21 \%$ & $26 \%$ & $18 \%$ & $12 \%$ & $22 \%$ & $21 \%$ & $14 \%$ & $19 \%$ & $25 \%$ & $22 \%$ & $21 \%$ & $18 \%$ & $19 \%$ & $21 \%$ & $22 \%$ \\
\hline & Completeness & ss of outcc & me measure & ement dat & ets for prescipt & tions & & & & & & & & & \\
\hline $\begin{array}{l}\text { Prescription } \\
\text { data of: }\end{array}$ & number of da & atasets & missing & complete & & number o & datasets & missing & complete & hess & number of & datasets & missing & complete & ness \\
\hline Antibiotics & 2765 & & 171 & $93.82 \%$ & & 3732 & & 117 & $96.86 \%$ & & 6497 & & 288 & $95.57 \%$ & \\
\hline $\begin{array}{l}\text { Benzodiazepines } \\
(20-74 y o)\end{array}$ & 2769 & & 167 & $93.97 \%$ & & 3732 & & 117 & $96.86 \%$ & & 6501 & & 284 & $95.63 \%$ & \\
\hline $\begin{array}{l}\text { Benzodiazepines } \\
(>74 y \mathrm{y})\end{array}$ & 2743 & & 193 & $92.96 \%$ & & 3732 & & 117 & $96.86 \%$ & & 6475 & & 310 & $95.21 \%$ & \\
\hline
\end{tabular}


Table 1 Demographic characteristics of privately and publicly owned primary care centres (PCC) (Continued)

\begin{tabular}{|c|c|c|c|c|c|c|c|c|c|c|c|c|}
\hline & \multicolumn{12}{|c|}{ Patient Perceived Quality (PPQ) (min 0- max 100 points) } \\
\hline & \multicolumn{4}{|c|}{ PPQ dataset completeness $99.11 \%$} & \multicolumn{4}{|c|}{ PPQ dataset completeness $96.25 \%$} & \multicolumn{4}{|c|}{ PPQ dataset completeness $97.40 \%$} \\
\hline & $\begin{array}{l}\text { mean } \\
\mathrm{PPQ}\end{array}$ & $\begin{array}{l}\text { recommend } \\
\text { PCC }\end{array}$ & access & continuity & mean PPQ & $\begin{array}{l}\text { recommend } \\
\text { PCC }\end{array}$ & access & continuity & mean PPQ & $\begin{array}{l}\text { recommend } \\
\text { PCC }\end{array}$ & access & continuity \\
\hline 2011 & $82.4(6.21)$ & $86.3(7.93)$ & $84.7(9.59)$ & $70.4(14.39)$ & $79.6(5.62)$ & $81.7(7.85)$ & $\begin{array}{l}80.18 \\
(9.45)\end{array}$ & $58.2(13.86)$ & $80.8(6.01)$ & $83.6(8.18)$ & $\begin{array}{l}82.1 \\
(9.75)\end{array}$ & $63.2(15.27)$ \\
\hline 2012 & $81.5(6.35)$ & $85.1(9.03)$ & $82.2(10.47)$ & $68.9(14.14)$ & $78.4(5.63)$ & $79.5(8.34)$ & $\begin{array}{l}78.4 \\
(9.47)\end{array}$ & $57.6(14.01)$ & $79.7(6.12)$ & $81.9(9.04)$ & $\begin{array}{l}80.0 \\
(10.05)\end{array}$ & $62.4(15.11)$ \\
\hline 2013 & $81.4(6.23)$ & $84.7(8.66)$ & $78(11.81)$ & $68.1(12.96)$ & $77.9(6.77)$ & $79.0(9.84)$ & $\begin{array}{l}77.5 \\
(10.24)\end{array}$ & $57.1(15.13)$ & $79.4(6.75)$ & $81.4(9.75)$ & $\begin{array}{l}77.9 \\
(10.91)\end{array}$ & $61.8(15.22)$ \\
\hline
\end{tabular}

Sample sizes, location and listed population with age, gender och socioeconomic characteristics. Completeness of datasets for drug prescription data. Results of the National Survey on Patient Perceived Quality (PPQ). Unless otherwise stated standard deviations in brackets. Abbreviations used in the table: $P C C=$ primary care centre, no. = number, $p o p .=$ population, $S D=$ standard deviation, $R G=$ relative growth 2014 compared to $2011, P P Q=$ Patient Perceived Quality, yo = years old, IHD = Ischemic heart disease, CNI Q1-5 Care Need Index quintile 1-5 


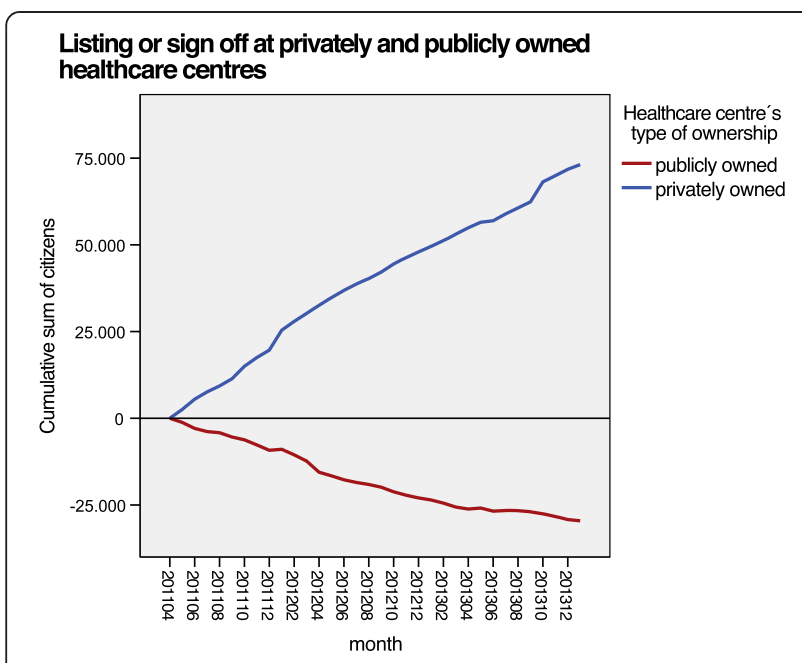

Fig. 1 Listing or sign off at privately and publicly owned healthcare centres

that the response rates of national survey of patient perceived quality are relatively low (51.3-53.4\%).

\section{Rate of purchased antibiotics}

The mean rate of purchased antibiotics prescribed by the group of privately owned PCCs (6.0 purchased prescriptions per quarter/100 listed citizens, SD 2.78) was steadily higher and had a larger variance than the mean rate of the group of publicly owned PCCs (5.1 purchased prescriptions per quarter/100 listed citizens, SD 1.50). Differences between the groups were largest in 2011 and decreased over time (Fig. 3 ). While the $10^{\text {th }}$ percentile of each group had rates that were similar, differences increased in the comparison of the $50^{\text {th }}$ to the $90^{\text {th }}$ percentile. Rates decreased for both groups and all subgroups but especially

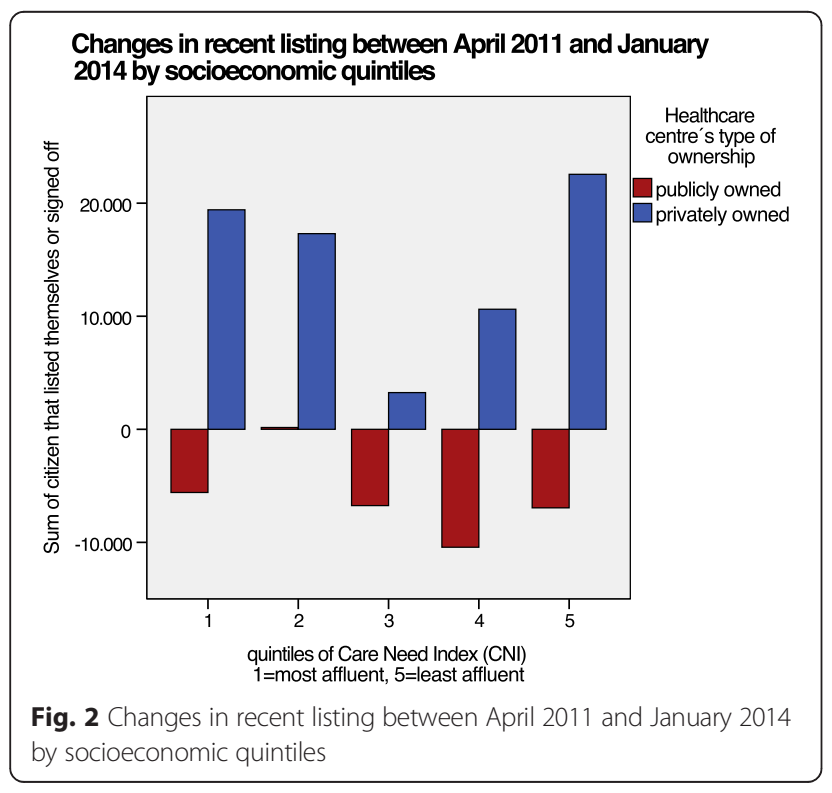

for the $90^{\text {th }}$ percentile of the group of privately owned PCCs after August 2012. Table 2 illustrates the finding that the group of publicly owned PCCs had lower rates compared to the group of privately owned PCCs, even when adjusted for mean CNI, gender, age structure and geographic location of the PCC.

\section{Rates of purchased benzodiazepine derivatives}

The rates of purchased benzodiazepine derivatives for elderly aged over 74 were in general more than fivefold higher than those for younger individuals aged 20-74 (on average 1771.17 vs. 293.81 DDD/100 patients/month). These internationally compared already high rates increased for all PCCs from 2011 to 2013 by $3.6 \%$ for younger individuals and by $7.4 \%$ for elderly individuals (Table 3 ). The group of privately owned centres showed a steadily lower mean of the rates for younger individuals with a higher variation than the group of publicly owned centres (277.98 DDD/ 100 patients/month, SD 151.66 vs. 305.56 DDD/100 patients/month, SD 103.46). The use of benzodiazepine derivatives for the elderly showed the same tendency between the two groups in 2011 but the relative differences diminished over time due to the fact that the group of privately owned PCCs increased their prescription rates from 2011 to 2013 more than twice as much as the group of publicly owned centres (increase rates $11.5 \%$ vs. $4.7 \%$ ). Variations in rates of purchased benzodiazepine between PCCs were in general large. Table 2 illustrates the fact that the group of privately owned PCCs showed a lower use of benzodiazepine derivatives even when adjusted for mean $\mathrm{CNI}$, gender and geographic location of the PCC. However, the $95 \%$ confidence interval reveals substantial variance. Rates for younger patients tended to be higher outside the regional metropolis, while the rates for older patients showed the reverse results.

\section{Follow-ups carried out for patients with chronic diseases}

The group of privately owned PCCs showed in comparison with the group of publicly owned PCCs lower rates of follow-ups carried out for patients with HPT $(66.6 \%$ vs. $70.9 \%)$, IHD (63.6 \% vs. $67.9 \%)$ and DM (83.4 \% vs. $85.0 \%)$ and higher variation for all three chronic diseases (Table 4). All rates of follow-ups carried out for patients with DM showed improvements over time regardless of ownership type; particularly the follow up for urine micro-albumin improved in the group of privately owned PCCs from 59.4 to $70.6 \%$. Rates of blood pressure measurements carried out for all three chronic diseases were between 82.5 and $94.5 \%$. Rates of the documentation of smoking habits for patients with IHD and HPT were only at $50.8-59.1 \%$ yet the same rates for patients with DM were 84.9-89.7\%. Rates of the documentation of LDL measurements were between 67.9 and $77.0 \%$ for patients with DM, and 55.3-60.5\% for patients with IHD. 
Table 2 Adjustments for Care Need Index, gender, age structure, size and location of primary care centre

\begin{tabular}{|c|c|c|c|c|}
\hline \multicolumn{5}{|l|}{ Patient perceived Quality (mean) } \\
\hline \multirow[t]{2}{*}{ Effect } & \multirow[t]{2}{*}{ Estimate } & \multirow[t]{2}{*}{ Standard error } & \multicolumn{2}{|c|}{$95 \%$ confidence interval } \\
\hline & & & Lower & Upper \\
\hline Intercept & 92.17 & 1.505 & 89.20 & 95.14 \\
\hline Publicly owned & -2.24 & 0.858 & -3.93 & -0.56 \\
\hline Privately owned & 0 & & & \\
\hline Year, 2011 & 1.10 & 0.568 & -0.02 & 2.22 \\
\hline Year, 2012 & 0.16 & 0.558 & -0.94 & 1.26 \\
\hline Year, 2013 & 0 & & & \\
\hline Publicly owned * year, 2011 & 0.69 & 0.738 & -0.76 & 2.14 \\
\hline Publicly owned * year, 2012 & 0.44 & 0.730 & -0.99 & 1.88 \\
\hline Publicly owned * year, 2013 & 0 & & & \\
\hline Privately owned * year, 2011 & 0 & & & \\
\hline Privately owned * year, 2012 & 0 & & & \\
\hline Privately owned * year, 2013 & 0 & & & \\
\hline $\mathrm{CNI}$ & -3.48 & 0.465 & -4.40 & -2.57 \\
\hline within regional metropolis & -1.78 & 0.732 & -3.23 & -0.34 \\
\hline outside regional metropolis & 0 & & & \\
\hline number of listed citizens (in 100) & -0.03 & 0.010 & -0.05 & -0.01 \\
\hline
\end{tabular}

\begin{tabular}{|c|c|c|c|c|}
\hline \multicolumn{5}{|c|}{ Prescription rates of benzodiazepine derivates for patients aged $20-74$} \\
\hline \multirow[t]{2}{*}{ Effect } & \multirow[t]{2}{*}{ Estimate } & \multirow[t]{2}{*}{ Standard error } & \multicolumn{2}{|c|}{$95 \%$ confidence interval } \\
\hline & & & Lower & Upper \\
\hline Intercept & -149.95 & 119.807 & -385.27 & 85.36 \\
\hline Publicly owned & 12.79 & 17.732 & -22.03 & 47.62 \\
\hline Privately owned & 0 & & & \\
\hline Year, 2011 & -12.49 & 19.367 & -50.53 & 25.55 \\
\hline Year, 2012 & -5.42 & 18.869 & -42.48 & 31.64 \\
\hline Year, 2013 & 0 & & & \\
\hline Publicly owned * year, 2011 & 4.4 & 25.219 & -45.14 & 53.93 \\
\hline Publicly owned * year, 2012 & 3.94 & 24.819 & -44.8 & 52.69 \\
\hline Publicly owned * year, 2013 & 0 & & & \\
\hline Privately owned * year, 2011 & 0 & & & \\
\hline Privately owned * year, 2012 & 0 & & & \\
\hline Privately owned * year, 2013 & 0 & & & \\
\hline $\mathrm{CNI}$ & 22.01 & 6.986 & 8.29 & 35.73 \\
\hline Proportion female & 821.64 & 234.167 & 361.7 & 1281.58 \\
\hline Proportion male & 0 & & & \\
\hline within regional metropolis & -50.99 & 10.714 & -72.03 & -29.95 \\
\hline outside regional metropolis & 0 & & & \\
\hline
\end{tabular}

Prescription rates of antibiotics Effect

Intercept

Publicly owned

Privately owned

Year, 2011

Year, 2012

Year, 2013

Publicly owned * year, 2011

Publicly owned * year, 2012

Publicly owned * year, 2013
Estimate Standard error $\quad 95 \%$ confidence interval

Lower Upper

$1.13 \quad 10.66$

$-1.83 \quad-0.77$

$\begin{array}{ll}-1.3 & 0.27\end{array}$

0

$0.89 \quad 0.287$

$0.89 \quad 0.280$

0

$-0.49$

$-0.43$

0
Prescription rates of benzodiazepine derivates for patients aged over 74

\begin{tabular}{lllll} 
Effect & Estimate & Standard Error & \multicolumn{2}{c}{$95 \%$ confidence interval } \\
& & & Lower & Upper \\
Intercept & 602.43 & 450.151 & -281.74 & 1486.59 \\
Publicly owned & 50.98 & 66.624 & -79.88 & 181.84 \\
Privately owned & 0 & & & \\
Year, 2011 & -201.67 & 72.766 & -344.59 & -58.75 \\
Year, 2012 & -135.76 & 70.896 & -275 & 3.49 \\
Year, 2013 & 0 & & &
\end{tabular}


Table 2 Adjustments for Care Need Index, gender, age structure, size and location of primary care centre (Continued) Privately owned * year, $2011 \quad 0 \quad$ Publicly owned * year, 2011 Privately owned * year, 2012

0

Privately owned * year, 2013

CNI

Proportion female

0.57

Proportion male

Proportion of 0-19

Proportion of 20-64

Publicly owned * year, 2012

Publicly owned * year, 2013

Privately owned * year, 2011

Privately owned * year, 2012

Privately owned * year, 2013

Proportion of $65+$

3.8

0.109

0.36

0.78

0

within regional metropolis

0.95

$-5.19$

1.877

1.811

$$
-2.73
$$

$-0.8$

outside regional metropolis

0.183

$-1.15$

$-0.44$

0

The estimates of the mean patient perceived quality, prescription rates of antibiotics and benzodiazepine derivatives per ownership type are calculated by a linear mixed model for repeated yearly observations (for the 197 PCCs with data during 2011-2013). Adjustments were made selectively for year, location, number of listed citizens (in 100), Care Need Index, proportion of gender group listed and proportion of age groups listed at PCC (0-19 years, 20-64 years and 65+). * indicates the interaction of two effects 


\section{Number of purchased prescriptions of antibiotics for a 3-month} period/100 listed

Using the raw data to plot the 10th (dashed line), 50th (solid line) and 90th percentile (dotted line) respectively

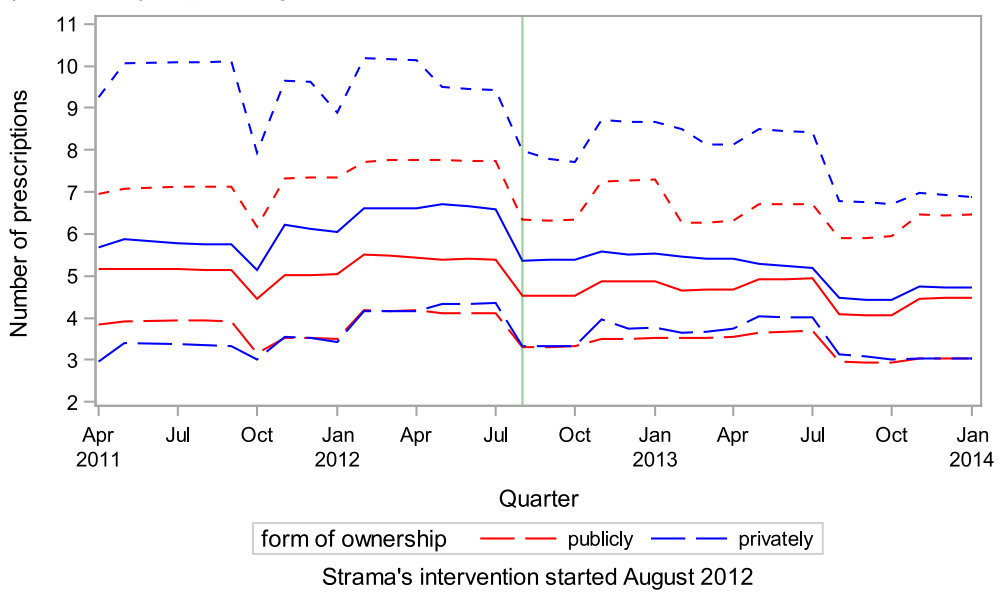

Fig. 3 Number of purchased prescriptions of antibiotics for a 3-month period/100 listed. Using the raw data to plot the 10th (dashed line), 50th (solid line) and 90th percentile (dotted line) respectively

\section{Discussion}

This study shows varying differences between the groups of privately and publicly owned PCCs in patient perceived quality, antibiotic use, the use of benzodiazepine derivatives and the rates of follow-ups carried out for patients with chronic diseases. However the findings of this study cannot unambiguously answer the question of whether or not the quality of primary healthcare services is influenced by the healthcare centre's type of ownership: while the group of privately owned PCCs rate higher in patient perceived quality and have a lower use of benzodiazepine derivatives, the group of publicly owned PCCs show a lower use of antibiotics and have higher rates of followups carried out for patients with chronic diseases. At the same time this study revealed the existing structural differences between these two groups of primary care providers: Privately owned PCCs were on average smaller, to a higher degree situated in the regional metropolis, had higher fractions of citizens within the second most affluent socioeconomic quintile and an overrepresentation of citizens of working age. In their turn, publicly owned PCCs were on average larger, to a higher degree situated outside the

Table 3 Prescription of benzodiazepine derivates

\begin{tabular}{|c|c|c|c|c|c|c|c|c|c|}
\hline \multirow[b]{2}{*}{ Year } & \multirow[b]{2}{*}{$\begin{array}{l}\text { Type of } \\
\text { owner-ship }\end{array}$} & \multicolumn{4}{|c|}{ For individuals aged between 20-74 } & \multicolumn{4}{|c|}{ For individuals $>74$ years of age } \\
\hline & & $\begin{array}{l}\text { Mean } \\
\text { DDD }\end{array}$ & $\begin{array}{l}\text { Standard } \\
\text { deviation }\end{array}$ & $\begin{array}{l}\text { Increase- rate } \\
\text { compared to } 2011\end{array}$ & $\begin{array}{l}\text { Deviation from mean } \\
\text { DDD for all PCCs }\end{array}$ & $\begin{array}{l}\text { Mean } \\
\text { DDD }\end{array}$ & $\begin{array}{l}\text { Standard } \\
\text { deviation }\end{array}$ & $\begin{array}{l}\text { Increase-rate } \\
\text { compared to } 2011\end{array}$ & $\begin{array}{l}\text { Deviation from mean } \\
\text { DDD for all PCCs }\end{array}$ \\
\hline \multirow[t]{3}{*}{2011} & publicly & 299.20 & 103.04 & & $4.83 \%$ & 1751.85 & 445.74 & & $2.70 \%$ \\
\hline & privately & 266.64 & 162.59 & & $-6.58 \%$ & 1643.16 & 740.16 & & $-3.68 \%$ \\
\hline & all PCCs & 285.42 & 132.49 & & & 1705.88 & 590.77 & & \\
\hline \multirow[t]{3}{*}{2012} & publicly & 309.19 & 105.49 & $3.34 \%$ & $3.91 \%$ & 1775.69 & 440.47 & $1.36 \%$ & $1.23 \%$ \\
\hline & privately & 281.73 & 151.34 & $5.66 \%$ & $-5.32 \%$ & 1724.35 & 578.87 & $4.94 \%$ & $-1.70 \%$ \\
\hline & all PCCs & 297.55 & 127.65 & $4.25 \%$ & & 1754.10 & 503.86 & $2.83 \%$ & \\
\hline \multirow[t]{3}{*}{2013} & publicly & 306.22 & 101.55 & $2.35 \%$ & $3.55 \%$ & 1833.08 & 433.27 & $4.64 \%$ & $0.03 \%$ \\
\hline & privately & 281.83 & 144.04 & $5.70 \%$ & $-4.70 \%$ & 1831.66 & 567.52 & $11.47 \%$ & $-0.04 \%$ \\
\hline & all PCCs & 295.74 & 122.21 & $3.61 \%$ & & 1832.47 & 494.94 & $7.42 \%$ & \\
\hline \multirow[t]{3}{*}{ Total } & publicly & 305.56 & 103.46 & & $4.00 \%$ & 1790.97 & 440.33 & & $1.12 \%$ \\
\hline & privately & 277.98 & 151.66 & & $-5.39 \%$ & 1744.23 & 623.95 & & $-1.52 \%$ \\
\hline & all PCCs & 293.81 & 126.98 & & & 1771.17 & 526.45 & & \\
\hline
\end{tabular}

Purchased prescriptions in defined daily doses (DDD) per 100 listed individuals at PCC, divided into age-group, year and type of ownership 
Table 4 Percentage of documented follow-ups carried out for certain chronic diseases

\begin{tabular}{|c|c|c|c|c|c|c|c|c|}
\hline \multirow[t]{2}{*}{ Chronic disease } & \multirow{2}{*}{$\begin{array}{l}\text { Patients with } \\
\text { documentation for }\end{array}$} & \multirow[t]{2}{*}{ Year } & \multicolumn{3}{|c|}{ Privately owned PCC } & \multicolumn{3}{|c|}{ Publicly owned PCC } \\
\hline & & & $\begin{array}{l}\text { Percentage } \\
\text { mean }\end{array}$ & SD & $\begin{array}{l}\text { Percentage data } \\
\text { completeness }\end{array}$ & $\begin{array}{l}\text { Percentage } \\
\text { mean }\end{array}$ & SD & $\begin{array}{l}\text { Percentage data } \\
\text { completeness }\end{array}$ \\
\hline \multirow[t]{19}{*}{ Diabetes mellitus (DM) } & \multirow[t]{3}{*}{$\mathrm{HbA1c}$ measurement } & 2011 & 91.1 & 8.53 & 98.8 & 90.8 & 8.06 & 100.0 \\
\hline & & 2012 & 92.9 & 7.63 & 100.0 & 92.5 & 5.20 & 100.0 \\
\hline & & 2013 & 94.5 & 5.40 & 98.8 & 94.2 & 5.78 & 100.0 \\
\hline & \multirow[t]{3}{*}{ blood pressure } & 2011 & 90.7 & 7.99 & 98.8 & 90.2 & 7.80 & 100.0 \\
\hline & & 2012 & 92.9 & 8.09 & 100.0 & 92.9 & 4.26 & 100.0 \\
\hline & & 2013 & 93.6 & 7.19 & 98.8 & 94.5 & 4.17 & 100.0 \\
\hline & \multirow[t]{3}{*}{ body mass index } & 2011 & 82.9 & 12.96 & 98.8 & 84.4 & 9.96 & 100.0 \\
\hline & & 2012 & 92.9 & 12.01 & 100.0 & 87.3 & 7.68 & 100.0 \\
\hline & & 2013 & 93.6 & 9.07 & 98.8 & 89.8 & 6.79 & 100.0 \\
\hline & \multirow[t]{3}{*}{ smoking status } & 2011 & 84.9 & 12.64 & 98.8 & 85.4 & 10.73 & 100.0 \\
\hline & & 2012 & 89.1 & 11.39 & 100.0 & 87.9 & 8.79 & 100.0 \\
\hline & & 2013 & 88.9 & 9.46 & 98.8 & 89.7 & 8.97 & 100.0 \\
\hline & \multirow[t]{3}{*}{ micro-albumin urine test } & 2011 & 59.4 & 24.54 & 98.8 & 74.2 & 17.73 & 100.0 \\
\hline & & 2012 & 68.4 & 22.49 & 100.0 & 75.6 & 17.28 & 100.0 \\
\hline & & 2013 & 70.6 & 19.3 & 98.8 & 76.7 & 16.46 & 100.0 \\
\hline & \multirow[t]{3}{*}{ low-density lipoprotein } & 2011 & 67.9 & 16.75 & 98.8 & 71.4 & 14.49 & 100.0 \\
\hline & & 2012 & 71.6 & 17.36 & 100.0 & 74.9 & 13.67 & 100.0 \\
\hline & & 2013 & 76.1 & 13.91 & 98.8 & 77.0 & 12.89 & 100.0 \\
\hline & average percentage & & 83.4 & 12.60 & 99.2 & 85.0 & 10.04 & 100.0 \\
\hline \multirow[t]{4}{*}{ Ischemic heart disease (IHD) } & blood pressure & 2012 & 82.5 & 8.27 & 89.7 & 84.1 & 6.23 & 99.1 \\
\hline & smoking status & 2012 & 53.0 & 17.52 & 78.9 & 59.1 & 14.06 & 98.2 \\
\hline & low-density lipoprotein & 2012 & 55.3 & 16.20 & 71.6 & 60.5 & 12.94 & 99.1 \\
\hline & average percentage & & 63.6 & 14.00 & 80.1 & 67.9 & 11.08 & 98.8 \\
\hline \multirow[t]{3}{*}{ Hypertension (absence of DM and IHD) } & blood pressure & 2012 & 82.4 & 9.14 & 96.4 & 83.9 & 7.45 & 99.1 \\
\hline & smoking status & 2012 & 50.8 & 21.12 & 93.8 & 57.8 & 14.5 & 99.1 \\
\hline & average percentage & & 66.6 & 15.13 & 95.1 & 70.9 & 10.98 & 99.1 \\
\hline
\end{tabular}

$S D=$ standard deviation

regional metropolis, had higher fractions of citizens within the second least affluent socioeconomic quintile and had an overrepresentation of juveniles and elderly.

The reader needs to consider an important limitation of this study as it is based on aggregated data and not on individual data, and as the differences between the two types of ownership were only analysed on the aggregated level for the whole county and do not include a multilevel analysis. Even if the location of the PCC (metropolitan vs. rural) was taken into account in the adjustments for confounding factors the geographical differences between the various parts of the county were not investigated. These limitations mean that there is a risk of an ecological inference fallacy and that conclusions can neither be drawn for any individual nor for any subarea of the county according the quality of healthcare services as there were variations within the two groups studied, as well as in each organizational unit. These variations might lead to completely different interpretations at the level of an individual or the level of a subarea compared to the aggregated level of the county. The application of a linearmixed model based on annual data was considered viable in this study as the residuals of this model showed a homogeneity of variances. However, due to the fact that a model on the basis monthly data would have shown relevant skewness, further methodological improvements should be considered: If logarithmized, data becomes less skewed and the geometric mean (the mean of the logarithmized data of all observations) becomes an estimate of the median. However, this does not provide information about certain subgroups of interest, i.e. PCCs with high prescription rates. Therefore further research is necessary including the development of a viable model using quantile regression. The research team addressed this problem in this study by choosing raw data plots to illustrate the prescription rates of antibiotics, being aware that this 
figure does not include the adjustment for explanatory factors and needed to be supplemented with the results of the above-mentioned mixed model.

Certain methodical weaknesses occur due to the imprecision of variables such as the fact that this study does not count the actual number of prescriptions made at a PCC but uses a proxy measures to describe the use of antibiotics and benzodiazepine derivatives at a PCC: through data from the Swedish eHealth Agency the number of purchased drugs which were prescribed at a certain PCCs is calculated, meaning that actual prescriptions rates can be higher as not all patients purchased the prescribed drugs. Datasets for antibiotic use were neither adjusted for age nor gender and nor was it necessarily connected to the patients listed at the PCC. This was partially addressed by adjustments for gender and age as higher rates of antibiotic use have been reported for the elderly and for females. It was not possible to adjust for some influencing factors such as the PCCs location, as PCCs on the coast had considerably higher prescription rates in summer caused by the number of tourists [34]. Further imprecision might have occurred as some GPs have used their PCC workplace code incorrectly during Out-of-hours services leading to spuriously higher rates of antibiotic use for their ordinary PCCs. With the regular publications via the Swedish Strategic Programme Against Antibiotic Resistance (Strama) in Region Västra Götaland, awareness of this error has increased among prescribers during the period studied, and thus the decrease in prescription rates at a few individual PCCs could be partly caused by a more correct use of the workplace code. Studies that were not susceptible to this as they included antibiotic prescriptions from all different prescribers support the finding of a generally decreased antibiotic use in the county [34]. The rates of purchased prescriptions of benzodiazepine derivatives could be biased by the fact that a pattern of many short patient visits at a PCC would reduce the rate due to the fact that it was the number of patients visiting the PCC that was counted in the denominator and not the number of listed citizens. While the datasets on DM and HPT generally showed high completeness, the datasets on IHD in the group of privately owned PCCs had a lower completeness level that is obstructive to the comparison. Technical obstacles leading to some missing data during the collection and aggregation of data at the regional healthcare authorities weaken the results of the study to some extent. Through the exclusion of Out-of-office services and single-handed practices due to lack of available data it was impossible to include all purchased prescriptions for the whole of primary care. Although methodical limitations of the national patient survey have been discussed in earlier reports, including the low patient response rates between 51.3 and $53.4 \%$ and the influence of socioeconomic and geographic factors, the results were valuable to some extent in the context of this group comparison [28].

On the other hand certain strengths in this study allowed researchers to obtain an extensive picture of quality of primary care services in the county studied. These strengths were the high completeness rates of almost all datasets and the inclusion of nearly the whole population. Furthermore as many as possible modifying factors for outcomes of the populations have been included in the adjustments such as the socioeconomic index, variations in gender and age structure and the size and location of the PCCs.

The finding that the group of privately owned PCCs steadily showed higher patient perceived quality than the group of publicly owned PCCs (even after adjustment for confounders) seems consistent with the finding that there was concurrently a continuous shift of patients from publicly owned PCCs to privately owned PCCs indicating that citizens who were less satisfied with the primary care services at publicly owned PCCs chose to register at privately owned PCCs (even if the results of the national patient survey have to be interpreted with caution due to methodical limitations). These findings of this study differ from a prior national study that included three counties (one third of all PCCs in Sweden) and revealed that privately owned PCCs received higher ratings in patient perceived quality than publicly owned PCCs but that this difference vanished after adjustment for the socioeconomic factors and the morbidity burden [28]. In general these findings have to be interpreted with caution as previous research in an international context showed a number of methodological problems and unresolved issues in patients perceived quality of care such as ceiling effects; uncertainty about whether instruments are reliable and valid across cultures and the continuing reliance in many surveys on ratings in which expectations are confounded with experiences [35].

In order to achieve a more rational use of antibiotics with a goal of 250 purchased prescriptions per 1000 inhabitants and year, Strama pronounced in the Region Västra Götaland a theoretical goal of an average for all PCCs of 3.1 purchased prescriptions/100 listed citizens and quarter. Due to varying preconditions, individual PCCs may have differing rates although guidelines for a rational antibiotic use are followed. However, the observed variation with the maximum rates at individual privately owned PCCs of up to ten times and at individual publicly owned PCCs of up to four times of the average theoretically aimed at, indicates that PCCs were either over-prescribing antibiotics or providing care for an exceptionally high number of patients with infectious diseases. The latter might be explained by an uneven distribution of these patients, which though is in conflict with the PCC's task to primarily provide care for their listed population. The findings of this study show that 
the use of antibiotics and the variations between PCCs decreased after August 2012 particularly for high-prescribing PCCs. Concurrently with the decrease, Strama became part of the regional administration in Västra Götaland and started an intervention lasting throughout the rest of the period studied. Beside information about antibiotic resistance, antibiotic prescribing guidelines and current prescribing patterns, it included the involvement of one General Practitioner (GP) from each PCC as a key person who initiated meetings with colleagues for the purpose of reflection [34]. Two behavioural studies conducted recently that investigated factors influencing Swedish GPs' use of antibiotics found four factors that supported a rational use: forums at PCCs for discussion on guidelines; leadership and support to local opinion leaders; inter-professional collaboration; and opportunities for professional development [36]. These findings support the assumption that Strama's intervention had an important impact on the greatest decrease nationwide of antibiotic prescriptions which occurred in the county during the period studied and which is well in accordance to the WHO's call for action against antimicrobial resistance. Compared internationally Sweden has a rather low and moreover decreasing rate of antibiotic use and has one of the lowest antibiotic resistance rates [37]. A recent study showed that poor governance and corruption-two factors under good control in Sweden - contribute beside usage volumes to the level of antibiotic resistance [38]. The same study also showed, without having a clear explanation, positive correlation between the percentage of private health expenditure in a country and the degree of antibiotic resistance, presuming in this sector fewer controls on broad-spectrum agents, the length of time of drug therapy and the volumes used.

The alarming finding that the already high rates of purchased prescriptions of benzodiazepine derivatives further increased in both groups, especially for elderly patients who are prone to several adverse effects, stands in contrast to the reduced use of antibiotics. But it corresponds well to earlier investigations that showed that GPs are averse to addressing the public health problem of benzodiazepine overuse in the elderly. GPs endorsed benzodiazepines as effective treatment for anxiety, citing quick action and strong patient satisfaction [39]. They stated as causes limited physician time and poor reimbursement for Mental Health Care as causes and complained about a lack of training in constructive strategies to address anxiety problems $[39,40]$. A recent review showed that supervised benzodiazepine withdrawal augmented by psychotherapy should be considered in older people-a resource-intensive therapy that stands in conflict with the situation of competing PCCs aiming to provide care for as many patients as possible [41]. Educational outreach visits on prescribing benzodiazepines to elderly in southern Sweden were effective in modifying GPs' prescribing habits [42]. The absence of a comparable comprehensive education program might explain the contradictory trends in the use of antibiotics and benzodiazepines. In order to address this unfavourable trend further investigations and evidence-informed interventions are necessary.

The findings concerning the rates of follow-ups carried out for patients with DM, IHD and HPT do not support the assumption that physicians might tend to register diagnoses in order to benefit from economic incentives although no adequate follow-up of the condition was carried out, which has been discussed in other settings [43]. Smaller variations between PCCs should be acceptable as reasonable practice forbids a strict adherence to guidelines particularly for the elderly as other questions related to person-focused care (e.g. quality at the end of life) can become more important and the allocation of resources must be considered wisely [44]. However this study does not contradict earlier findings that change of reimbursement system elevates rates of diagnoses [45].

The two different quality registries involved (NDR and QregPV) have been in existence for different lengths of time. NDR, which is nationwide and has been established for longer shows generally higher rates of follow-ups carried out. This indicates a need for further research on how the acceptance and usage of a registry influences healthcare routines [46].

In recent years patients' and medical professionals' perceptions, patients' opportunities for informed choices and the effects of patients' choices associated with the reforms in Swedish primary healthcare have been studied $[2,6,9,28]$. The findings of this study revealed, even if it cannot unambiguously answer the question of whether or not the quality of primary healthcare services is influenced by the healthcare centre's type of ownership, that the two groups differ structurally (geography and size of the PCCs) and in the composition of the population served. Additionally the variation in outcome measures was higher at privately owned PCCs. Furthermore, both favourable and disadvantageous trends occur simultaneously and the patient perceived quality was on a group level not consistent with the other outcome measures. As healthcare in European countries in the recent years has become to some extent more private, studies have been carried out to evaluate the effects [47]. However, a recent review stated that the evidence for recurring privatisation questions is weak and mixed [48]. The public-private mix in Swedish primary healthcare has changed substantially with consequences difficult to predict while the lack of data and neglect of research in this field have hindered informed policy-making [49]. It can be questioned if the competition- and incentiveoriented approach of the recent Swedish reforms can contribute to sustainable improvements in the quality of primary healthcare services. The unequal distribution of 
the population (concerning socio-economy and geography and age) to the two different groups of primary care providers correspond well to prior findings like the increased probability of choosing a publicly owned PCC instead of a privately owned one, the older the individual and the higher the comorbidity level [50]. These effects were certainly not intended by the healthcare reform and their impact on future trends including other effects on i.e. recruitment of medical professionals remains unclear. Future reforms that aim to create an effective and sustainable primary care system should therefore be evidenceinformed and continuously evaluated through close cooperation of health service researchers and policy makers.

\section{Conclusions}

The findings of this study cannot unambiguously answer the question of whether or not the quality of primary healthcare services is influenced by the healthcare centre's type of ownership. However they question the political prediction that the most recent healthcare reform including a shift of power from officials to citizens and an increase of providers and their diversity would create conditions that encourage care providers to improve the quality and efficiency of care. As the quality of primary healthcare services showed concurrently improvements and impairments in the different studied outcomes it can be questioned whether the competitive environment encouraged quality improvements. The detected tendencies of an unintended unequal distribution of the population between the two types of ownership with disparities in agegroups, socio-economy and geography might imply unpredictable consequences for the recruitment of scarce health care professionals (e.g. General Practitioners) and thus risk an equal care provision. A continuous observation of effects and further studies and are needed to elucidate possible causal relations and to enable evidence-informed policy-making.

\section{Competing interests}

Beside their research activities AM, PS, JT and CB are employed part-time or full-time at the publicly owned primary healthcare organisation Närhälsan in Region Västa Götaland. PS is part of the regional Strama team.

\section{Authors' contributions}

AM study design, data collection, analysis, preparation of the manuscript. CW study design, analysis, consistency in the manuscript. PS analysis, consistency in the manuscript. JT study design, analysis, consistency in the manuscript. CB study design, analysis, consistency in the manuscript. All authors read and approved the final manuscript.

\section{Authors' information}

Not applicable.

\section{Acknowledgements}

We would like to thank the regional healthcare authorities for providing the data.

\section{Author details}

${ }^{1}$ Department of Medicine, Division of General Practice, University Medical Centre Freiburg, Elsässerstr. 2 m, D-79110 Freiburg, Germany. ${ }^{2}$ Institute for Quality Management and Social Medicine, University Medical Centre Freiburg, Engelbergerstr. 21, D-79106 Freiburg, Germany. ${ }^{3}$ Department of Public Health and Community Medicine/Primary Health Care, Institute of Medicine, The Sahlgrenska Academy, University of Gothenburg, Box 454SE-405 30 Göteborg, Sweden. ${ }^{4}$ Centre for Applied Biostatistics, The Sahlgrenska Academy, University of Gothenburg, Box 414SE-405 30 Göteborg, Sweden. ${ }^{5}$ Research and Development Unit, Primary Health Care in Southern Älvsborg County, Sven Eriksonsplatsen 4, SE-503 38 Borås, Sweden.

Received: 10 November 2014 Accepted: 18 September 2015

Published online: 26 September 2015

\section{References}

1. The National Board of Health and Welfare. National Board Statutes (SOSFS). Stockholm: Quality Management and Patient Safety in Health Care; 2005. Swedish.

2. Anell A. Choice and privatisation in Swedish primary care. Health Econ Policy Law. 2011;6:549-69.

3. Anell A, Glenngard AH, Merkur SM. Sweden: Health system review. Health Syst Transit. 2012;14:1-159.

4. Sweden's State Auditor (Riksrevisionen). RiR 2014:22 Primary Care Governance - According to Need or Demand? Swedish: Stockholm; 2014.

5. Carlsson L, Börjesson U, Edgren L. Patient based "burden-of-illness" in Swedish primary health care. Applying the Johns Hopkins ACG case-mix system in a retrospective study of electronic patient records. Int J Health Plann Manag. 2002;17:269-82.

6. Glenngård $A H$, Anell A, Beckman A. Choice of primary care provider: Results from a population survey in three Swedish counties. Health Policy. 2011;103:31-7.

7. Janlöv N, Andersson A, Beckman A. Who Has Been Favored by the Reform for the Free Choice of Care Provider? A Comparative Study between Three Counties before and after the Introduction in Primary Care. 1st ed. Stockholm: Agency for health care analysis; 2013. Swedish.

8. Maun A, Nilsson K, Furåker C, Thorn J. Primary healthcare in transition - a qualitative study of how managers perceived a system change. BMC Health Serv Res. 2013;13:382.

9. Holmberg S, Ekström H. Primary health care in Kronoberg before and after the care choice. More satisfied patients... the staff think it got worse. Lakartidningen. 2014;111:1128-30.

10. Woolhandler S, Himmelstein DU. The high costs of for-profit care. CMAJ. 2004; 170:1814-5.

11. Cabin W, Himmelstein DU, Siman ML, Woolhandler S. For-profit medicare home health agencies' costs appear higher and quality appears lower compared to nonprofit agencies. Heal Aff. 2014;33:1460-5.

12. Kondilis E, Gavana M, Giannakopoulos S, Smyrnakis E, Dombros N, Benos A. Payments and quality of care in private for-profit and public hospitals in Greece. BMC Health Serv Res. 2011;11:234.

13. Chaix-Couturier C, Durand-Zaleski I, Jolly D, Durieux P. Effects of financial incentives on medical practice: results from a systematic review of the literature and methodological issues. Int J Qual Health Care. 2000;12:133-42.

14. Gosden T, Forland F, Kristiansen IS, Sutton M, Leese B, Giuffrida A, et al. Impact of payment method on behaviour of primary care physicians: a systematic review. J Health Serv Res Policy. 2001;6:44-55.

15. Fenton JJ, Jerant AF, Bertakis KD, Franks $P$. The cost of satisfaction: $A$ national study of patient satisfaction, health care utilization, expenditures, and mortality. Arch Intern Med. 2012;172:405-11.

16. Costelloe C, Metcalfe C, Lovering A, Mant D, Hay AD. Effect of antibiotic prescribing in primary care on antimicrobial resistance in individual patients: systematic review and meta-analysis. BMJ. 2010;340:c2096-6.

17. Macfarlane J, Holmes W, Macfarlane R, Britten N. Influence of patients' expectations on antibiotic management of acute lower respiratory tract illness in general practice: questionnaire study. BMJ. 1997;315:1211-4.

18. Working Group on mobilization against narcotic drugs: Over-prescription of narcotic drugs - analysis and action. Stockholm. 2005. Swedish. http://www.drogfritt-bromolla.se/dokument/balldin_total.pdf. Accessed 3 Sept 2015

19. Ridderbjelke C, Abrahamsson P-A: The Use of Sleep Medications and Sedative Drugs in Västra Götaland. 2014. Swedish. http://epi.vgregion.se/ 
upload/L\%C3\%A4kemedel/Anv\%C3\%A4ndning\%20av\%20s\%C3\%B6mnl \%C3\%A4kemedel\%20och\%20lugnande\%20l\%C3\%A4kemedel\%20i\%20 VGR\%20REK\%20frossan\%202014.pdf. Accessed 3 Sept 2015

20. Von Elm E, Altman DG, Egger M, Pocock SJ, Gøtzsche PC. Vandenbroucke JP, for the STROBE Initiative:

The Strengthening the Reporting of Observational Studies in Epidemiology (STROBE) Statement: Guidelines for reporting observational studies. Int J Surg. 2014:12(12):1495-9.

21. Region Västra Götaland: Primary Care. http://www.vgregion.se/sv/VastraGotalandsregionen/st artsida/Vard-och-halsa/Forvardgivare/VG-Primarvard1/ (2015) Swedish. Accessed 3 Sept 2015

22. Statistics Sweden. http://www.scb.se/en_/ (2015) Accessed 3 Sept 2015

23. Swedish National Survey on Patient Perceived Quality. http://npe.skl.se/ (2015) Swedish. Accessed 3 Sept 2015

24. National Prescribed Drug Register. http://www.socialstyrelsen.se/register/ halsodataregister/lakemedelsregistret (2015) Swedish. Accessed 3 Sept 2015

25. Swedish eHealth Agency. http://www.ehalsomyndigheten.se/Om-oss-/ Uppdrag-och-verksamhet/Other-languages $1 /$ Swedish-eHealth-Agency/ (2015) Swedish. Accessed 3 Sept 2015

26. Gudbjörnsdottir S, Cederholm J, Nilsson PM, Eliasson B. The National Diabetes Register in Sweden An implementation of the St. Vincent Declaration for Quality Improvement in. Diabetes Care. 2003;26:1270-6.

27. Quality Registry of the region of Western Sweden: Annual rapport of the Quality Registry of the region of Western Sweden - QregPV. https://stratum.registercentrum.se/Handlers/ ResourceManager.ashx?|D=31707 (2012) Swedish. Accessed 3 Sept 2015

28. Glenngård AH, Anell A. What Affects the Patient Perceived Quality in Primary Care? Stockholm: Agency for health care analysis. 1st ed. 2012. Swedish.

29. Barnett K, Mercer SW, Norbury M, Watt G, Wyke S, Guthrie B. Epidemiology of multimorbidity and implications for health care, research, and medical education: a cross-sectional study. Lancet. 2012;380:37-43.

30. Sundquist K, Malmström M, Johansson S-E, Sundquist J. Care Need Index, a useful tool for the distribution of primary health care resources. J Epidemiol Community Health. 2003;57:347-52.

31. Mölstad S, Erntell M, Hanberger H, Melander E, Norman C, Skoog G, et al. Sustained reduction of antibiotic use and low bacterial resistance: 10-year follow-up of the Swedish Strama programme. Lancet Infect Dis. 2008;8:125-32.

32. Ai W. The defined daily dose system (DDD) for drug utilization review. Hosp Pharm. 1986;21:233-4. 239-41, 258.

33. Donoghue J, Lader M. Usage of benzodiazepines: A review. Int J Psychiatry Clin Pract. 2010;14:78-87.

34. Public Health Agency of Sweden. Swedish Work on Containment of Antibiotic Resistance. Solna: Uppsala; 2014.

35. Sofaer S, Firminger K. Patient Perceptions of the Quality of Health Services. Annu Rev Public Health. 2005:26:513-59.

36. Public Health Agency of Sweden: What Influcences General Practitioners When Prescribing Antibiotics?. https://www.folkhalsomyndigheten.se/ documents/om-folkhalsomyndigheten/uppdrag-styrdokument/avslutade/ faktorer-som-paverkar-lakare-vid-forskrivning-av-antibiotika.pdf (2014) Swedish. Accessed 3 Sept 2015

37. Adriaenssens N, Coenen S, Versporten A, Muller A, Minalu G, Faes C, et al. European Surveillance of Antimicrobial Consumption (ESAC): outpatient antibiotic use in Europe (1997-2009). J Antimicrob Chemother. 2011;66 suppl 6:vi3-vi12.

38. Collignon P, Athukorala P, Senanayake S, Khan F. Antimicrobial Resistance: The Major Contribution of Poor Governance and Corruption to This Growing Problem. PLoS One. 2015;10:e0116746.

39. Cook JM, Marshall R, Masci C, Coyne JC. Physicians' perspectives on prescribing benzodiazepines for older adults: a qualitative study. J Gen Intern Med. 2007;22:303-7.

40. Bendtsen P, Hensing G, McKenzie L, Stridsman AK. Prescribing benzodiazepines-a critical incident study of a physician dilemma. Soc Sci Med. 1999;49:459-67.

41. Gould RL, Coulson MC, Patel N, Highton-Williamson E, Howard RJ. Interventions for reducing benzodiazepine use in older people: meta-analysis of randomised controlled trials. Br J Psychiatry J Ment Sci. 2014;204:98-107.

42. Midlöv P, Bondesson $\AA$, Eriksson T, Nerbrand C, Höglund P. Effects of educational outreach visits on prescribing of benzodiazepines and antipsychotic drugs to elderly patients in primary health care in southern Sweden. Fam Pract. 2006;23:60-4.

43. Hill H, Hill M. The ethics of coding: are we committing fraud? Physician Assist. 2011:24:67-8.

44. Petursson H, Getz L, Sigurdsson JA, Hetlevik I. Current European guidelines for management of arterial hypertension: Are they adequate for use in primary care? Modelling study based on the Norwegian HUNT 2 population. BMC Fam Pract. 2009;10:70.

45. Hjerpe $P$, Boström KB, Lindblad $U$, Merlo J. Increased registration of hypertension and cancer diagnoses after the introduction of a new reimbursement system. Scand J Prim Health Care. 2012;30:222-8.

46. Gliklich RE, Dreyer NA. Registries for Evaluating Patient Outcomes: A User's Guide. 2nd edition. Rockville (MD). US: Agency for Healthcare Research and Quality; 2010.

47. Maarse $\mathrm{H}$. The privatization of health care in Europe: an eight-country analysis. J Health Polit Policy Law. 2006;31:981-1014.

48. Braithwaite J, Travaglia JF, Corbett A. Can questions of the privatization and corporatization, and the autonomy and accountability of public hospitals, ever be resolved? Health Care Anal. 2011;19:133-53.

49. Ovretveit J. Nordic privatization and private healthcare. Int J Health Plann Manag. 2003;18:233-46.

50. Zielinski A, Håkansson A, Beckman A, Halling A. Impact of comorbidity on the individual's choice of primary health care provider. Scand J Prim Health Care. 2011:29:104-9.

\section{Submit your next manuscript to BioMed Central and take full advantage of:}

- Convenient online submission

- Thorough peer review

- No space constraints or color figure charges

- Immediate publication on acceptance

- Inclusion in PubMed, CAS, Scopus and Google Scholar

- Research which is freely available for redistribution

Submit your manuscript at www.biomedcentral.com/submit
C) BioMed Central 